\title{
Game Analysis on Technology Innovation Purchase under Complete Information
}

\author{
Zhang Guoliang ${ }^{\mathrm{a}}$, Li Fengxiang ${ }^{\mathrm{b}}$ \\ ${ }^{a, b}$ School of economics \& management, Shenyang Institute of Aeronautical Engineering, Shenyang, China
}

\begin{abstract}
In the fierce market competition, technological innovation becomes a crucial element which effects the sustainable development of enterprises. That enterprises buy technology from the external could save limited resources, so more resources could be put into core business. The external purchase of innovative technology is essentially the results of the game between enterprise and innovative research institutions. The two players in the game analyze counterpart's policy to choose the best strategy to achieve the greatest benefits.
\end{abstract}

Index Terms: Complete Information; Innovative Technology; Game; Strategy; Benefits

(C) 2011 Published by MECS Publisher. Selection and/or peer review under responsibility of the International Conference on E-Business System and Education Technology

\section{Introduction}

In the fierce market competition, many enterprises utilize technological innovation to enhance their core competitiveness which has now become a common choice. At present, technological innovation becomes a crucial element effecting the sustainable development of enterprises. Under the condition of limited resources, internal innovation cost is much too high. To solve this problem, lots of enterprises purchase technological innovation from external Innovative research institutions. This purchase process can be seen as a game participated by enterprises and Innovative research institutions, which two both devote exclusive attention to maximum profit and obviously will make positive response strategies to the other player's

\section{Theory Reviewing}

Scholars both domestic and abroad have researched on these related topics. Many scholars overseas researched on cooperative innovation between high schools and enterprises. For example, Rustum Roy studied several modalities for high schools and enterprises cooperation, and tabled proposals [1]. David Blumenthal thought, risk and interest coexist in the relationship between high schools and enterprises [2]. Challenges high school faced are to manage this relation and try to minimize risk and reserve interests. Also, domestic scholars

Corresponding author:

| E-mail address: ${ }^{\text {shzhg1@ 163.com }}$; $^{\text {ch lifengxiang@126.com }}$ 
made some similar studies, e.g. Chen Cheng [3] etc analyzed cooperative game between Reach party and enterprises in the circumstances of independent research, cooperative development, exclusive dealing and non-exclusive dealing. Ye Xiaoqing [4] etc studied reasons of technology transaction in asymmetric information circumstances, and explained adverse selection occurred. These studies mostly based on incomplete information, but enterprises' purchase of technological innovation under complete information scarcely involved. This article established kinds of static and dynamic game models on technological innovation purchase behavior, to provide theoretical basis and to give some advice to the related departments and authorities.

\section{Establishing and Solving Stalic Models}

The innovative technology external purchase of enterprises is essentially the results of the game with innovative research institutions. The main idea of the game is to put yourself in your opponent's position to think.

It is known that, the possibility of success will be increased if the two players create a win-win situation. Enterprises and innovative research institutions will seek for a win-win or win-lose strategy concerning with interests to highest their income when the former purchase from external.

\subsection{Conditions}

This article mainly researches complete information games between enterprises and external innovative research institutions .To simplify the analysis, four conditions are assumed as follows:

- There are only two players exist in the game: the buyer (enterprises) and the seller (innovative research institutions). Both are rational economic men;

- No government intervention exists here;

- When choosing, the player considers the other one's strategy given, without regard to affection on the other decision maker;

- The two players do not know counterpart's action before their decision made.

Based on the assumed conditions above, a one-time game model within complete information can be built, regardless of time (Zhang Weiying [5], 1996).

\subsection{Static Game Models Analysis}

Providing that, the seller obtains $u$ through unreserved transfer of innovative technology and earns $v$ when reserved (later, he could transfer reserved parts to other buyers), obviously $\mathrm{u}<\mathrm{v}$. Risks and losses need to be taken and suffered for the reserved seller, rising from lawsuit, reputation damage, creditworthiness decreasing, etc. caused by reserving or transferring once again. The buyer's expected utility $\mathrm{w}$ is a function regarding the value of innovative technology bought. Generally, only when $w>0$, does the buyer want to purchase. According to the foregoing assumption (4), the two players do not know counterpart s' action before their decision made, so we can believe their action are simultaneous. This game is a static game of complete information. The payoff table is as follows.

In table 1, rs and (1-rs) are probabilities of the seller choosing unreserved or reserved transfer action, also, $\mathrm{rb}$ and (1-rb) are probabilities of the buyer whether purchase or not.

If $u>v-\phi$, unreserved strategy would be the seller's optimal strategy whether the buyer purchase or not. Take the buyer into account. He would get $w$ utilities through purchasing strategy when the seller unreserved, in contrast, when the seller reserved, he would not purchase and earn 0 . It is observed that, $(\mathrm{u}, \mathrm{v})$ is the only 
Nash equilibrium point, and (to purchase, unreserved) is the stable solution of this game. This is corresponded to the fact that only when the seller unreserved does the buyer purchase.

If $u<v-\phi$, for the seller, unreserved earning would be less. It belongs to the mixed strategy game. If the seller's choice is unreserved, the buyer's best strategy is to buy, however, the seller's best strategy is reserved when the buyer's option is to buy ,then, instead, the buy's best strategy is not to buy, so repeatedly, and the two parties cannot find solidified interests. Either participant can change its policy in any strategy combinations to get more profits. This problem is a mixed strategic issue under complete information.

Table 1. The Payoff Table

\begin{tabular}{cccc}
\hline & & \multicolumn{2}{c}{ The seller } \\
\cline { 2 - 4 } The buyer & To Purchase: $r b$ & Unreserved: $r s$ & Reserved: $(1-r s)$ \\
\cline { 2 - 4 } & Not to purchase: $(1-r b)$ & $w, u$ & $-w, v-\varphi$ \\
\hline
\end{tabular}

To set up, mixed strategy is (rb,1-rb) to the buyer and ( $\mathrm{rs}, 1-\mathrm{rs})$ to the seller. When the strategy (rs,1-rs) to the seller is known, the buy's expected utility could be extrapolated.

$$
w_{b}=r_{b}\left[r_{s} w+\left(1-r_{s}\right)(-w)\right]+\left(1-r_{b}\right)\left[r_{s} \times 0+\left(1-r_{s}\right) \times 0\right]
$$

By partial differentiation, optimization purchase strategy for the buyer is that,

$$
r_{s} w+\left(1-r_{s}\right)(-w)=0
$$

Then, $r s=1 / 2$.

When the strategy (rb,1-rb) to the buyer is known, the seller's expected utility is as follows.

$$
w_{s}=r_{s}\left[r_{b} u+\left(1-r_{b}\right) \times 0\right]+\left(1-r_{s}\right)\left[r_{b}\right](v-\phi)+\left(1-r_{b}\right)(-\phi)
$$

Then, optimization purchase strategy for the buyer is as follows.

$$
r_{b} u-r_{b}(v-\phi)+\left(1-r_{b}\right)(-\phi)=0
$$

Then $r_{b}=\phi /(v-u)$

Therefore, $(1 / 2,1 / 2)$ and $(\phi /(v-u), 1-\phi /(v-u))$ are mixed strategy Nash equilibrium.

When $u=v-\phi$, for the seller, the revenue is the same attributable to unreserved strategy and reserved strategy. To attract more buyers, the seller would choose unreserved strategy. Therefore (to purchase, unreserved) is stable solution for the game, that is to say, only the seller choosing unreserved strategy does the buyer want to purchase, which is close to the fact [6]. 


\section{Dynamic Game Analysis under Complete Information}

In the static analysis above, pursuing of short-time gain, the seller is apt to choose reserved strategy. Even if the two participants adopt a mixed strategy, expected utility they got would not be so perfect. In the long run, the buyer purchasing or not depends on judgment of the seller's reserved or unreserved strategy. Therefore, concerned with long-time benefit, the seller would adopt the unreserved strategy to form a expectation in the interest of himself. When the buyer's expectation comes to nothing, he would affect other buyers' behaviors through lawsuits, exposure etc and then affect the buy's long-time profits. The static game model hereby can be extended as that, proceeding buyers are not fixed, considering the seller providing technology transfer to a buyer as a stage of repetitive game. Assume every buyer purchases once and knows whether the seller reserved or not before. This time the game can be considered as dynamic game under complete information. Sub-game Nash Equilibrium consists in this game [5]. So long as the seller unreserved transfers all the time, sellers would purchase in every stage. However, if the seller reserved once, sellers would believe this conduct may continue and do not purchase. The result (to purchase, unreserved) is a Nash Equilibrium that the buyer receives $\mathrm{w}$ utilities and the seller gets u income.

The seller's strategy analysis is as follows. Suppose if the buyer purchases, the seller chooses reserved strategy and gains short-time revenue v- $\emptyset$. For repeated games, when he knows the seller reserved, the following buyers would not transact with him. Then the seller would get no profit. However, if he unreserved, he gains $u$ earnings in every transaction. Set $\mathrm{i}(\mathrm{i}>0)$ as profit margin, $\mathrm{n}$ as repeated game stages. When $\mathrm{n}$ goes to infinity, the seller's present value of earnings is $\mathrm{R}$.

$$
R=\mathrm{u}+u(1+i)^{-1}+u(1+i)^{-2}+\ldots+u(1+i)^{-n}=u(1+i) / i
$$

Requirement for the seller to unreserved transfer is as the following inequality.

$$
v-\phi \leq R
$$

Put algebraic expression (6) into (5), then, $v-\phi \leq u(1+i) / i$, after simplified,

$$
(v-\phi-u) * i=u
$$

When $v-\phi \leq u$, inequality (6) holds. The seller's long-time earnings out of unreserved strategy are more than those out of short-time and reserved strategy. To gain long-time revenue, unreserved strategy is a optimal strategy to uphold. This game can repeat forever.

If $v-\phi$ less than but close to $\mathrm{u}$, the seller's expected earnings is lower, and i is much smaller than average rate of profit $r$, which can support formula (6). Namely, the seller's long-time earnings out of unreserved strategy are much more than those out of reserved strategy. Obviously, he would choose unreserved strategy.

If $v-\phi$ is much less than $\mathrm{u}$, the seller would get more super profit out of reserved strategy. Then i have to much higher than $\mathrm{r}$, which is hard to achieve, so there is high risk. At this time, the seller would prefer reserved strategy.

According to the above-mentioned analysis and the condition (6), the earning difference between unreserved 
and reserved strategy is $v-\phi-u$. when $v-\phi-u>u / r$, reserved strategy is feasible for the seller. Therefore, $u / r$ is a critical point.

Take the buyers' strategy into account. Every one cares about his earnings, only when he is sure about the seller's unreserved strategy, does he transacts with him and purchases his technology. If the seller reserved once, sellers would believe this conduct may continue, then their optimal option is not to transact with him [7].

\section{Conclusion}

Purchasing technology innovation from the external is an inevitable choice for enterprises to increase innovation efficiency. The article established complete information models about enterprises purchasing from external, then analyzed enterprises' and innovation research institutes' strategies in every model.

This paper analysis is under complete information, however, in fact, there are under incomplete information circumstances. Additional, in this paper, games between government and the seller, sellers and sellers are not involved. These need further consideration.

\section{References}

[1] Rustum R. University-industry interaction patterns. Science. New Series. 1972.178 (4064): 955-960.

[2] Michael Porter. The Competitive Advantage of nations. Beijing: Citic Publishing House.

[3] Chen Cheng \&Liu Hedong. Cooperative Innovation among Industry, Colleges and R\&D Institutes under Incomplete Information. Science and Technology Management Research. 2009(9):428-430.

[4] Ye Xiaoqing \& Xu Yu. A Non-symmetric Information Game Analysis on Industry-university Cooperative Innovation. Science Research Management. 2003(5): 88-91.

[5] Zhang Weiying. 1959. The Analytics of Uncertainty and Information. Shanghai: Shanghai People's Publishing House.

[6] Wang Meng. A Research on Game Relationship in Technical Alliance of Enterprises. Dalian: Dalian University of Technology.

[7] Yan Qingyou \& Li Yingying. Game Analysis of Outside Information Licensing. Journal of North China Electric Power University 